\title{
Circulating soluble adhesion molecules in patients with giant cell arteritis. Correlation between soluble intercellular adhesion molecule-1 (sICAM-1) concentrations and disease activity
}

Blanca Coll-Vinent, Carme Vilardell, Carme Font, Joaquim Oristrell, José Hernández-Rodríguez, Jordi Yagüe, Álvaro Urbano-Márquez, Josep M Grau, Maria C Cid

\begin{abstract}
Objective-To evaluate whether changes in concentrations of circulating adhesion molecules are related to disease activity in patients with giant cell arteritis (GCA). Methods-A sandwich ELISA was used to measure soluble intercellular adhesion molecule-1 (sICAM-1), sICAM-3, vascular cell adhesion molecule-1 (sVCAM-1), E-selectin (sE-selectin), and L-selectin (sL-selectin) in serum and plasma samples from patients with GCA. A cross sectional study was performed on 64 GCA patients at different activity stages and on 35 age and sex matched healthy donors. Thirteen of these patients were evaluated at the time of diagnosis and serially during follow up. Results-At the time of diagnosis, sICAM-1 concentrations were significantly higher in active GCA patients than in controls (mean (SD) 360.55 (129.78) $\mathrm{ng} / \mathrm{ml}$ versus $243.25(47.43) \mathrm{ng} / \mathrm{ml}, \mathrm{p}<0.001)$. In contrast, sICAM-3, sVCAM-1, sE-selectin, and sL-selectin values did not differ from those obtained in normal donors. With corticosteroid administration, a decrease in sICAM-1 concentrations was observed, reaching normal values when clinical remission was achieved (263.18 (92.7) $\mathrm{ng} / \mathrm{ml}$ globally, $293.59(108.39) \mathrm{ng} / \mathrm{ml}$ in the group of patients in recent remission, and 236.83 (70.02) $\mathrm{ng} / \mathrm{ml}$ in those in long term remission). In the 13 patients followed up longitudinally, sICAM-1 values also normalised with clinical remission (225.87 (64.25) $\mathrm{ng} / \mathrm{ml}$ in patients in recent remission, and $256.29(75.15) \mathrm{ng} / \mathrm{ml}$ in those in long term remission).

Conclusions-Circulating sICAM-1 concentrations clearly correlate with clinically apparent disease activity in GCA patients. Differences with results previously found in patients with other vasculitides may indicate that different pathogenic mechanisms contribute to vascular inflammation in different disorders.
\end{abstract}

(Ann Rheum Dis 1999;58:189-192)

Giant cell (temporal) arteritis (GCA) is a large vessel vasculitis that affects mostly elderly people. Histologically, it is characterised by a lymphocyte and macrophage infiltration of large and medium sized vessels that frequently exhibits a granulomatous pattern with giant cell formation. There is no specific treatment for this disease, although GCA patients present a favourable clinical and biological response to corticosteroids. However, relapses are not infrequent when corticosteroids are tapered or discontinued, and accurate parameters discriminating persistent subclinical inflammatory activity from true remission have not been identified.

Important contributions have currently improved our understanding of the immunopathogenic mechanisms involved in the development of GCA lesions. $\mathrm{T}$ lymphocytes infiltrating the temporal arteries seem to be activated by specific recognition of a putative antigen residing in the arterial wall and, subsequently, activate macrophages, which undergo a functional differentiation and contribute to vessel inflammation and damage through various pathways (see reviews by $\mathrm{Cid}$ et $a l^{1}$ and Weyand and Goronzy ${ }^{2}$ ).

Independently of the primary immunopathogenic mechanisms, the development of inflammatory infiltrates requires dynamic interactions between leucocyte surface adhesion receptors and their ligands on the endothelial cell surface (reviewed by Springer ${ }^{3}$ ). Circulating forms of these adhesion molecules have been detected in human serum and plasma and increased concentrations have been detected in disorders where leucocyte/endothelial cell interactions play a significant part, namely infections, neoplasms, and chronic inflammatory diseases. ${ }^{4}$ The role that circulating adhesion molecules play in vivo is not well known. It has been suggested that increased circulating concentrations of soluble adhesion molecules may reflect endothelial or leucocyte activation, or both. ${ }^{5}$

In this study, we measured circulating concentrations of soluble ICAM-1, ICAM-3, VCAM-1, E-selectin, and L-selectin in a large and homogeneous series of patients with biopsy verified GCA to define the pattern of circulating adhesion molecules in GCA patients and to evaluate whether changes in soluble adhesion molecule concentrations are related to disease activity.

\section{Methods}

PATIENTS

The study group consisted of 64 biopsy verified GCA patients (18 men and 46 women) aged 74 years (range $57-88$ ). 
Table 1 Concentrations of the adhesion molecules studied in the cross sectional study (ng/ml)*

\begin{tabular}{|c|c|c|c|c|c|}
\hline \multirow[b]{2}{*}{$\begin{array}{l}\text { Adhesion } \\
\text { molecule }\end{array}$} & \multirow[b]{2}{*}{ Active patients $(n=45)$} & \multicolumn{3}{|l|}{ Patients in remission } & \multirow[b]{2}{*}{ Controls $(n=35)$} \\
\hline & & $\begin{array}{l}\text { Recent remission } \\
(n=13)\end{array}$ & $\begin{array}{l}\text { Long term remission } \\
(n=15)\end{array}$ & Total $(n=28)$ & \\
\hline sICAM-1 & $360.55(129.78) \dagger \ddagger$ & $293.59(108.385)$ & $236.83(70.02)$ & $263.18(92.71)$ & $243.25(47.43)$ \\
\hline sICAM-3 & $38.4(20.6)$ & $44.64(23)$ & $43.71(20.829)$ & $44.14(21.46)$ & $35.26(24.674)$ \\
\hline sVCAM-1 & $705.21(278.84)$ & $817.76(508.69)$ & $622.34(353.1)$ & $713.07(435.32)$ & $661.19(254.64)$ \\
\hline sE-selectin & $44.46(28.6)$ & $50.36(33)$ & $39.84(26.02)$ & $43(27.82)$ & $38.33(31.12)$ \\
\hline sL-selectin & $540.13(321.07)$ & $627.03(407.68)$ & $652.63(402.33)$ & $641.25(397.04)$ & $467.34(233.95)$ \\
\hline
\end{tabular}

${ }^{\star}$ Data are presented as mean $(\mathrm{SD}) .+\mathrm{p}$ compared with controls $<0.001$. $\neq \mathrm{p}$ compared with patients in remission $<0.01$.

A cross sectional study was performed, and patients were classified according to their disease activity. GCA was considered active when patients were clinically symptomatic and evaluated before starting treatment (prednisone $1 \mathrm{mg} / \mathrm{kg} /$ day). Patients were considered to be in remission when they fulfilled all the following conditions: (a) none of the GCA related signs or symptoms present at the time of diagnosis was present anymore, (b) there were no new signs or symptoms attributable to GCA, and (c) erythrocyte sedimentation rate (ESR) was within the normal range. Among them, we considered separately patients treated for one month to two years in whom remission was mantained with corticosteroid treatment (recent remission), and patients who, having been treated for at least two years, no longer were receiving corticosteroids (long term remission).

Data concerning clinical manifestations at diagnosis were obtained prospectively in patients with active disease and in those in recent remission. In patients in long term remission, clinical manifestations at presentation were obtained from their records. Disease activity was evaluated prospectively in all patients. Clinical features recorded were age, sex, duration of symptoms before biopsy, and the presence or absence of the following: polymyalgia rheumatica, cranial symptoms (headache, scalp tenderness, jaw claudication), ischaemic symptoms (amaurosis, diplopia, cerebrovascular accident), and systemic inflammatory response (fever, weight loss, ESR > $85 \mathrm{~mm} \mathrm{1st} \mathrm{h,}$ haemoglobin < $110 \mathrm{~g} / \mathrm{l})$.

The control group included 35 healthy blood donnors (10 men, 25 women) aged 73 years (range 60-88).

For the cross sectional study, 73 determinations (49 serum samples, 24 plasma samples) were made: 45 in active GCA patients, and 28 in patients in remission (13 in recent remission and 15 in long term remission).

A longitudinal substudy was done with 13 active patients who underwent serial determinations at diagnosis (with no treatment), when in complete remission one month to two years after starting corticosteroid treatment (recent remission), and when in long term remission, no longer receiving treatment. None of these patients experienced significant relapses during their follow up. For that reason, months/years after the start of treatment were considered equivalent to months/years in clinical remission.
SOLUBLE ADHESION MOLECULE DETECTION All samples were analysed for sICAM-1, sICAM-3, sVCAM-1, sE-selectin, and sLselectin values by sandwich ELISA according to the instructions of the manufacturer. We used commercially available kits from British Biotechnology Products, Abingdon, UK, for sICAM-1, sVCAM-1, and sE-selectin (BBE $1 \mathrm{~B}, \mathrm{BBE} 2 \mathrm{~B}$, and $\mathrm{BBE} 3 \mathrm{~B}$ respectively), and kits from Bender Medsystems, Vienna, Austria, for sICAM-3 and sL-selectin (BMS 218 and BMS 206 respectively).

STATISTICAL ANALYSIS

Data are presented as means (SD). For the cross sectional study, a Kruskal-Wallis $H$ test was used, correcting $\mathrm{p}$ values for multiple comparisons. For the longitudinal study, a Wilcoxon's rank sum test was used, also correcting $\mathrm{p}$ values for multiple comparisons. The MannWhitney $U$ test was used for comparisons between two groups. Pearson's correlation coefficient was used to correlate continuous variables. p Values (two tailed) less than 0.05 were considered significant.

\section{Results}

No differences were found between serum and plasma concentrations of SICAM-1, SICAM-3, sVCAM-1 nor sL-selectin $(\mathrm{p}=0.42,0.86$, 0.17 , and 0.35 respectively). Plasma sEselectin concentrations were significantly lower than serum concentrations $(\mathrm{p}<0.01)$. Therefore, for sE-selectin, only serum samples were considered.

Soluble ICAM-1 concentrations in active patients (360.55 (129.78) $\mathrm{ng} / \mathrm{ml})$ were increased compared with controls (243.25 $(47.43) \mathrm{ng} / \mathrm{ml})(\mathrm{p}<0.001)$. Soluble ICAM-1 concentrations were higher in active patients than in patients in clinical remission, both when these were considered globally (263.18 (92.7) $\mathrm{ng} / \mathrm{ml}, \mathrm{p}<0.01$ ), and when only patients in long term remission were considered (236.83 (70.02) ng/ml, p < 0.01). Circulating sICAM-1 values in patients in clinical remission did not differ from normal donors. No significant differences were observed, either, between patients in recent remission (293.59 $(108.385) \mathrm{ng} / \mathrm{ml}$ ) compared with those in long term remission (table 1 ).

No statistical differences were found in sICAM-3, sVCAM-1, sE-selectin, and sLselectin values between active patients and controls, nor between active patients and patients in remission (table 1 ). 


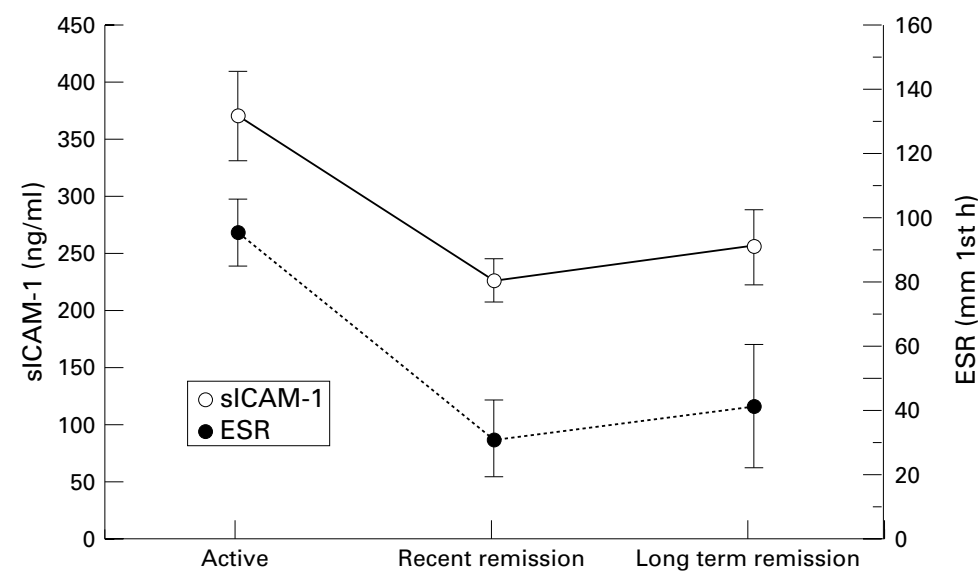

Figure 1 Soluble ICAM-1 concentrations and ESR values in the longitudinal study. Error bars show standard error of the mean.

A significant correlation was found between the number of inflammatory parameters, as defined in the methods section, and sICAM-1 concentrations $(p<0.05)$. No relation was observed between circulating concentrations of any other adhesion molecule studied and the clinical features recorded.

Figure 1 shows the results from the longitudinal substudy. In keeping with the data obtained from the cross sectional study, sICAM-1 values decreased when clinical remission was achieved (from 369.63 (139.17) to $225.87(64.25 \mathrm{ng} / \mathrm{ml}), \mathrm{p}<0.01)$, and remained at low concentrations when treatment was stopped (256.29 (75.15) ng/ml). A correlation was found between sICAM-1 concentrations and ESR values (Pearson's correlation coefficient, $p=0.034$ ). No significant variation of any of the other adhesion molecules studied was observed in the longitudinal study.

\section{Discussion}

Our results indicate that SICAM-1 values were increased in patients with active GCA compared with values found in healthy matched controls. Subsequently, sICAM-1 returned to normal when clinical remission was achieved. In contrast, circulating sICAM-3, sVCAM-1, sE-selectin, and sL-selectin concentrations remained unmodified throughout the course of the disease.

Circulating adhesion molecules have been studied in a variety of vasculitis syndromes. Most of these studies include small series of miscellaneous patients with different vasculitides and, therefore, conclusions are difficult to draw. Studies performed in homogeneous groups of patients have shown increased concentrations of SICAM-1 and SVCAM-1, but not sE-selectin, in patients with active Wegener's granulomatosis. ${ }^{6}$ Increased $\mathrm{sE}$ selectin and sICAM-1 concentrations have also been demonstrated in patients with Kawasaki disease. ${ }^{7}$ We have previously demonstrated an increase in circulating sICAM-1, sVCAM-1, sE-selectin, and a decrease in sL-selectin concentrations in patients with classic polyarteritis nodosa. ${ }^{8}$ Variations in the circulating pattern of soluble adhesion molecules in different vasculitides indicate a high complexity in the regulatory pathways involved in adhesion molecule expression and release and, probably, a diversity in the source of circulating adhesion molecules in each condition.

Immunopathological studies performed on biopsy specimens obtained from homogeneous series of patients with GCA and patients with polyarteritis nodosa have demonstrated E-selectin, ICAM-1, and VCAM-1 expression in endothelia of inflammed vessels, particularly in the adventitial microvasculature and neovessels. Strong ICAM-1 and ICAM-3 expression as well as occasional VCAM-1 expression have also been observed in infiltrating leucocytes. ${ }^{9} 10$ However, and in contrast with our previous findings in polyarteritis nodosa, ${ }^{8}$ only sICAM-1 was significantly increased in serum samples from GCA patients. GCA involves large arteries whereas polyarteritis nodosa involves medium and small sized vessels. Consequently, the endothelial surface contributing to the potential release of adhesion molecules is much wider in polyarteritis nodosa than in GCA. This fact could account for the increased concentration of sE-selectin, sICAM-1, and sVCAM-1 found in polyarteritis nodosa and the lack of significantly increased concentrations of adhesion molecules of endothelial origin in GCA.

Interestingly, the pattern of circulating adhesion molecules in our GCA patients is similar to that found by Macchioni et $a l^{11}$ and Meliconi et $a l^{12}$ in patients with polymyalgia rheumatica, a condition closely related to GCA. Patients with isolated polymyalgia rheumatica lack significant inflammatory vascular lesions in their arteries. Accordingly, it is not likely that increased SICAM-1 found in both conditions is generated in inflammed arteries. Circulating activated monocytes are a characteristic feature in both GCA and polymyalgia rheumatica ${ }^{13}$ and ICAM-1 is strongly expressed by activated cells of the monocytic lineage. ${ }^{3}$ Activated circulating monocytes could be a possible source of increased circulating sICAM-1 found in GCA and polymyalgia rheumatica, given the absence of increase of circulating values of other adhesion molecules of endothelial origin.

In vitro studies demonstrate that corticosteroid treatment down regulates adhesion molecule expression. ${ }^{14}$ According to this, we found that raised concentrations of circulating sICAM-1 returned to normal values upon corticosteroid treatment in our GCA patients. The longitudinal study showed a good correlation between sICAM-1 concentrations and clinically apparent disease activity and acute phase response as assessed by ESR measurement. A decrease in sICAM-1 concentrations upon corticosteroid treatment was also observed in the cross sectional study although, because different patients were included in each group, it was less apparent. In a previous study, we showed that increased concentrations of circulating soluble endothelial adhesion molecules persist in patients with polyarteritis nodosa despite corticosteroid treatment. ${ }^{8}$ We have also shown persistence of abnormally high levels of other products of endothelial origin such as vWFAg in GCA patients. ${ }^{15}$ The clear decrease in circulating sICAM-1 induced by corticosteroid 
treatment further supports a role for activated circulating monocytes as a source of sICAM-1 in GCA patients as this cell subset is very sensitive to the down regulatory effects of corticosteroids. $^{13}$

Changes in circulating adhesion molecules follow distinct patterns in different inflammatory diseases and show a certain level of specificity even in related syndromes such as the different vasculitides. Studying fluctuations of adhesion molecules along disease outcome may improve our understanding about the participation of different cell types in the pathogenesis of the inflammatory reaction in different disorders, the assessment of subclinical disease activity and the effects of treatment on specific pathophysiological mechanisms.

We thank Dr Àlex de la Sierra for his advice on statistical analysis. Blanca Coll-Vinent is a research award recipient from Hospital Clínic i Provincial de Barcelona. This work was partially supported by a grant from FIS n ${ }^{\circ} 95 / 0860$ and $n^{\circ} 98 / 0443$.

1 Cid MC, Font C, Coll-Vinent B, Grau JM. Large vessel vasculitides. Curr Opin Rheumatol 1998;10:18-28.

2 Weyand CM, Goronzy JJ. Giant cell arteritis is an antigen-driven disease. Rheum Clin North Am 1995;21: 1027-39.

3 Springer TA. Traffic signals for lymphocyte recirculation and leukocyte emigration: The multistep paradigm. Cell and leukocyte emig

4 Gearing AJH, Newman W. Circulating adhesion molecules Gearing AJH, Newman W. Circulating adhesion

5 Cid MC, Coll-Vinent B, Grau JM. Adhesion molecules in the interactions between leukocytes, the endothelium and the extracellular matrix (II). Clinical relevance and potential therapeutic applications. Med Clin (Barc) 1997;108 503-11.
6 Stegeman CA, Tervaert JWC, Huitema MG, Jong PE, Kallenberg CGM. Serum levels of soluble adhesion molecules intercellular adhesion molecule 1 , vascular cell adhesion molecule 1, and E selectin in patients with Wegener's granulomatosis. Arthritis Rheum 1994;37:1228-35.

7 Furukawa S, Imai K, Matsubara T, Yone K, Yachi A, Okumura $\mathrm{K}$, et al. Increased levels of circulating intercellular adhesion molecule-1 in Kawasaki disease. Arthritis Rheum 1992;35:672-7.

8 Coll-Vinent B, Grau JM, López-Soto A, Oristrell J, Font C, Bosch X, et al. Circulating adhesion molecules in patients with classical polyarteritis nodosa. $\mathrm{Br} \mathrm{J}$ Rheumatol 1997;36:1178-83.

9 Cid, MC, Cebrián M, Font C, Coll-Vinent B, Sánchez E, López-Soto A, et al. Cell adhesion molecules in the development of inflammatory infiltrates in giant cell arteritis opment of inflammatory infiltrates in giant cell

10 Coll-Vinent B, Cebrián M, Cid MC, Font C, Esparza J, Juan $M$, et al. Dynamic pattern of endothelial cell adhesion molecule expression in muscle and perineural vessels from patients with classical polyarteritis nodosa. Arthritis Rheum 1998;41:435-44.

11 Macchioni P, Boiardi L, Meliconi R, Salvarani C, Uguccioni MC, Rossi F, et al. Elevated soluble intercellular adhesion molecule 1 in the serum of patients with polymyalgia rheumatica: influence of steroid treatment. J Rheumatol 1994;21:1860-4.

12 Meliconi R, Pulsatelli L, Melchiorri C, Frizziero L, Salvarani C, Macchioni $\mathrm{P}$, et al. Synovial expression of cell adhesion molecules in polymyalgia rheumatica. Clin Exp Immunol 1997;107:494-500.

13 Roche N, Fulbright JW, Wagner AD, Hunder GG, Goronzy $\mathrm{JJ}$, Weyand CM. Correlation of interleukin-6 production and disease activity in polymyalgia rheumatica and giant cell arteritis. Arthritis Rheum 1993;36:1286-94.

14 Cronstein BN, Kimmel SC, Levin RI, Martiniuk F, Weissman G. A mechanism for the antiinflammatory effects of corticosteroids: the glucocorticoid receptor regulates leukocyte adhesion to endothelial cells and expression of endothelial-leukocyte adhesion molecule 1 and intercellular adhesion molecule 1. Proc Natl Acad Sci (USA) 1992;89:9991-5.

15 Cid MC, Monteagudo J, Oristrell J, Vilaseca J, Pallarés L, Cervera R, et al. Von Willebrand factor in the outcome of temporal arteritis. Ann Rheum Dis 1996;55:927-30. 